\title{
The Factors Influencing the Accuracy of Head Position During Canalith Reposition Procedure Using 9 Axis Inertial Sensor
}

\author{
Hyung Sun Hong', Ki Nam Kim, Chang Bin Yun', Jin Gu Kang', Hyun Ji Kim, \\ Sangmin Lee $^{2}\left(\mathbb{D}\right.$, and Kyu-Sung Kim $^{1}{ }^{(D)}$ \\ ${ }^{1}$ Department of Otorhinolaryngology-Head and Neck Surgery, Inha University College of Medicine, Incheon; and \\ ${ }^{2}$ Department of Electronic Engineering, College of Engineering, Inha University, Incheon, Korea
}

9축 관성센서를 이용하여 측정한 이석정복술의 정확도와 그에 영향을 주는 요소들

홍형선 ${ }^{1} \cdot$ 김기남 ${ }^{1} \cdot$ 윤창빈 $^{1} \cdot$ 강진구 $^{2} \cdot$ 김현지 $^{1} \cdot$ 이상민 $^{2} \cdot$ 김규성 $^{1}$

인하대학교 의과대학 이비인후-두경부외과학교실, ${ }^{1}$ 인하대학교 공과대학 전자공학과 ${ }^{2}$

\author{
Received July 15, 2019 \\ Revised August 7, 2019 \\ Accepted August 26, 2019 \\ Address for correspondence \\ Kyu-Sung Kim, MD, PhD \\ Department of Otorhinolaryngology- \\ Head and Neck Surgery, \\ Inha University College of Medicine, \\ 27 Inhang-ro, Jung-gu, \\ Incheon 14913, Korea \\ Tel $+82-32-890-3570$ \\ Fax +82-32-890-3580 \\ E-mail stedman@inha.ac.kr \\ Sangmin Lee, $\mathrm{PhD}$ \\ Department of Electronic Engineering, \\ College of Engineering, Inha University, \\ 100 Inha-ro, Michuhol-gu, \\ Incheon 22212, Korea \\ Tel +82-070-8256-1549 \\ Fax $+82-32-868-3654$ \\ E-mail sanglee@inha.ac.kr
}

Background and Objectives The canalith reposition procedure (CRP) is used for the treatment of benign paroxysmal positional vertigo (BPPV) where the accuracy of position may affect the therapeutic efficacy. We investigate the accuracy of head position in CRP and its influencing factors during the procedure by measuring the position using inertial sensors and three dimensional remodeling.

Subjects and Method We included 28 patients who were diagnosed as BPPV. To evaluate the accuracy of the CRP, we used the inertial sensor on the patient's goggle used for videonystagmography. We evaluated the accuracy of the treatment compared to the textual treatment used during CRP. We also evaluated patient factors that affected the accuracy of head position as well as analyzing the correlation between the error rate and the successful treatment rate.

Results While the average error rate was $12.6 \pm 5.8 \%$ for the PSCC group, it was $10.2 \pm 5.2 \%$ for the lateral semicircular canal (LSCC) group. For the posterior semicircular canal (PSCC) the group with body mass index (BMI), less than 25 patients had the lower error rate than the group with BMI greater than 25. There was no significant differences regarding the error rate according to BMI or age in the PSCC group. There is no significant differences regarding the error rate between those treated within 1 week and those over 1 week. For the LSCC delayed treatment group, there was no significant differences of error rate between the 1st and 2nd maneuver at each position.

Conclusion For the Epley maneuver, the error rate of patients with high BMI is higher than those with low BMI. When the repeated barbeque maneuver was conducted, patients could have a more accurate position due to the learning effect. Care should be taken to ensure accurate CRP by considering various factors. Korean J Otorhinolaryngol-Head Neck Surg 2020;63(4):154-62

Key Words Benign paroxysmal positional vertigo $\cdot$ Inertial Sensor · Vertigo.

\section{서 론}

양성 돌발 두위현훈(benign paroxysmal positional ver- tigo, BPPV)은 어지럼으로 내원한 환자의 가장 흔한 질환이 며, 모든 어지럼 환자의 17 42\%가 양성 돌발성 두위현훈으 로 진단되는 것으로 알려져 있다. ${ }^{1,2)} \mathrm{BPPV}$ 는 1달 이내에

This is an Open Access article distributed under the terms of the Creative Commons Attribution Non-Commercial License (https://creativecommons.org/licenses/by-nc/4.0) which permits unrestricted non-commercial use, distribution, and reproduction in any medium, provided the original work is properly cited. 
$20 \%, 3$ 달 이내에 $50 \%$ 의 환자에서 자발적으로 호전되지만, ${ }^{3,4)}$ $\mathrm{BPPV}$ 에 대한 치료로 가장 권고되는 것은 이석정복술(particle repositioning maneuver)이다. ${ }^{5)}$ 이석정복술의 치료 성 공률은 뒤반고리관 이석증의 경우 57 100\%, 가쪽 반고리관 이석증의 경우 60 98\%로 알려져 있다. ${ }^{6,7)}$ 비록 이석정복술 의 치료율은 높지만 $\mathrm{BPPV}$ 환자는 어지럼으로 인한 낙상이 나 일상생활 수행에 문제가 생길 위험이 높기 때문에 진단되 지 않은 BPPV와 치료되지 않은 BPPV의 임상적 및 삶의 질 에 대한 영향은 굉장히 크다. ${ }^{8}$ 또한 $\mathrm{BPPV}$ 는 재발이 흔한 질 환으로 이전의 연구에 따르면 증상의 재발로 이석정복술을 반복한 환자가 3 명 중 1 명까지 보고되고 있다..$^{9-11)}$

$\mathrm{BPPV}$ 와 관련된 이전의 연구들은 임상적으로 이석정복술 의 치료 결과에 연관된 환자의 인자들에 대한 연구들이 주 를 이루었으며, ${ }^{12,13)}$ 측두골 전산화단층촬영을 자료를 이용하 여 3차원 그래픽으로 전정미로의 해부학적 구조에 대해 분 석한 연구도 있었다. ${ }^{14)}$ 관성센서를 이용한 연구는 주로 스포 츠 의학이나 재활 의학 분야에서 이루어지는 경우가 많았으 며, 이러한 연구들로 관성센서를 이용하여 정확한 자세나 위 치 등의 정보를 얻는 기술이 많은 발전을 이루었다. 한편 이 석정복술의 원리는 이환된 반고리관의 방향에 맞춰 부유 이 석이 빠져나가도록 중력의 방향에 따라 머리의 위치를 움직 이는 것으로, 반고리관의 해부학적 특성뿐 아니라, 이석정복 술 시 적절한 두위를 위치시키고 유지하는 것이 치료 효과에 영향을 줄 수 있으나 이에 대한 연구가 미비하다.

이에 본 연구에서 9축 관성 센서를 이용하여 이석정복술 의 시행 시 각 두위의 정확도 및 이에 영향을 주는 환자의 요소, 오차율과 이석정복술 치료 결과에 대해 분석하여, $\mathrm{BPPV}$ 치료에 유용한 정보를 제공하고자 하였다.

\section{대상 및 방법}

본 연구는 2018년 1월 2019년 3월까지 어지럼증을 주소로 본원에 내원한 환자 중 병력 청취와 체위 안진 검사를 통해 $\mathrm{BPPV}$ 로 확진받은 환자 28 명을 대상으로 하였다. 처음 내원 하였을 때 병력과 비디오 안진 검사상 BPPV로 진단받은 환 자들 중 1 주일 후 재내원 시 전정신경염이나 중추성 병변 등 으로 진단이 바뀐 환자들은 제외하였다. 환자들은 비디오 안 진 검사를 시행받았으며, 2008년 미국 이비인후과 학회에서 발표한 BPPV 임상 진료 지침에 따라 체위 검사를 시행하였 고, ${ }^{5)}$ 검사 결과에 따라 환측 및 이환된 반고리관을 확인하여 Epley 수기 혹은 바비큐 회전 수기를 시행받았다. 이석정복술 을 시행받은 환자들은 1 주일 후 외래에 재방문하여 다시 체 위 검사를 시행하였으며, 체위 검사 시 안진 및 증상이 소실
되었을 때 치료된 것으로 판단하였다. 각 자세마다 오차율을 계산하기 위해 Epley 수기는 자세별로 각 단계를 나누어 3개 의 자세로 나누어 분석하였으며, 자세 1 은 환자의 고개를 병 변측으로 $45^{\circ}$ 돌린 후 뒤로 눕혀 수평보다 $20^{\circ}$ 정도 낮은 자세 이며 자세 2 는 자세 1 에서 환자의 고개를 건측으로 $90^{\circ}$ 돌린 자세이고, 자세 3은 같은 방향으로 머리와 몸통을 더 돌려 얼굴이 바닥을 향하고 있는 자세이다. 바비큐 회전 수기는 자세별로 5 개의 자세로 나누어 분석하였으며, 그대로 누운 자세에서 병변측으로 $90^{\circ}$ 고개를 돌린 상태를 자세 1로 하여 건측 방향으로 $90^{\circ}$ 씩 돌릴 때마다 자세 $2,3,4,5$ 로 정하였다 (Fig. 1).

9축 관성 센서는 자이로3축, 지자기3축, 가속도3축 센서를
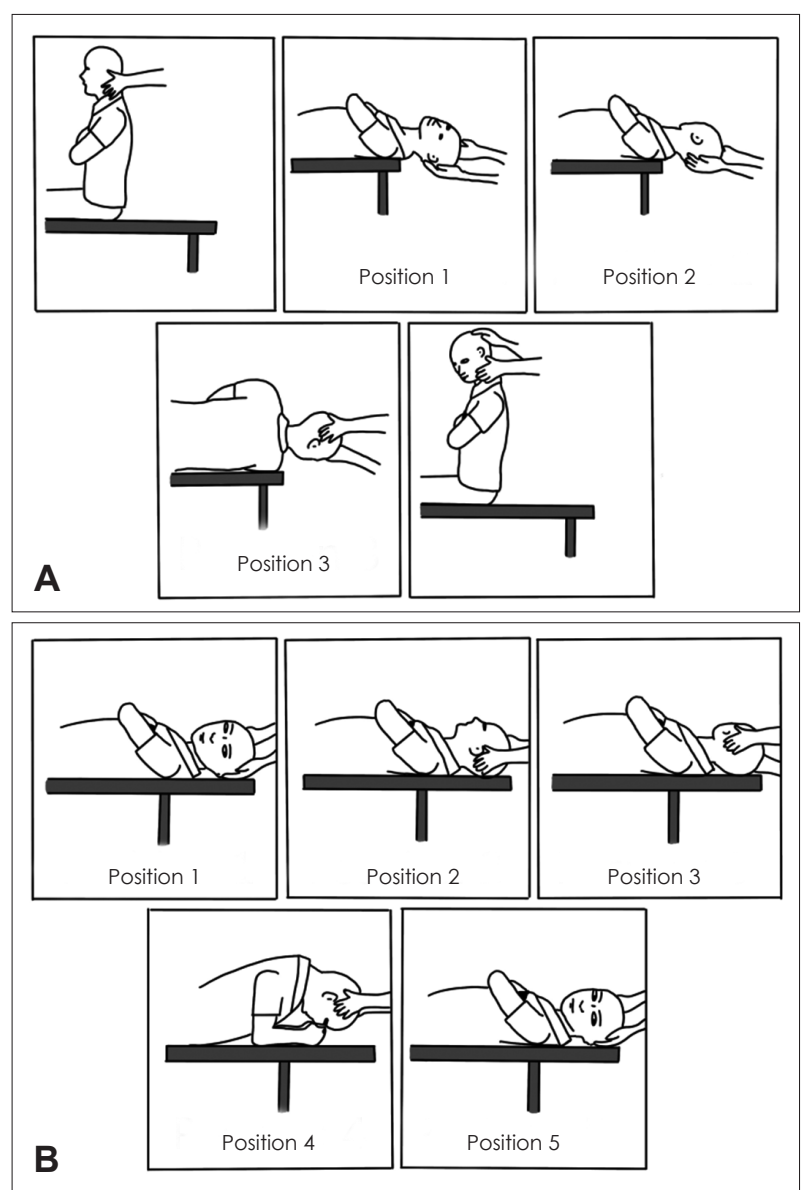

Fig. 1. Canalith repositioning procedures for posterior canal and lateral canal benign paroxysmal positional vertigo. Eply maneuver was divided into 3 stages. In the position 1, the patient's head was turned $45^{\circ}$ to the lesion side and then laid back and lowered $20^{\circ}$ lower than the horizontal level. Position 2 is the posture that the patient's head is turned $90^{\circ}$ to the unaffected side from the position 1 , and position 3 is the posture that the face is facing the floor by turning the head and the trunk in the same direction (A). The barbeque maneuver was divided into 5 positions according to the posture. The posture of $90^{\circ}$ head turned to the affected side in a lying position was set as posture 1 , and the the postures $2,3,4$, and 5 were set every turn $90^{\circ}$ to the unaffected side (B). 

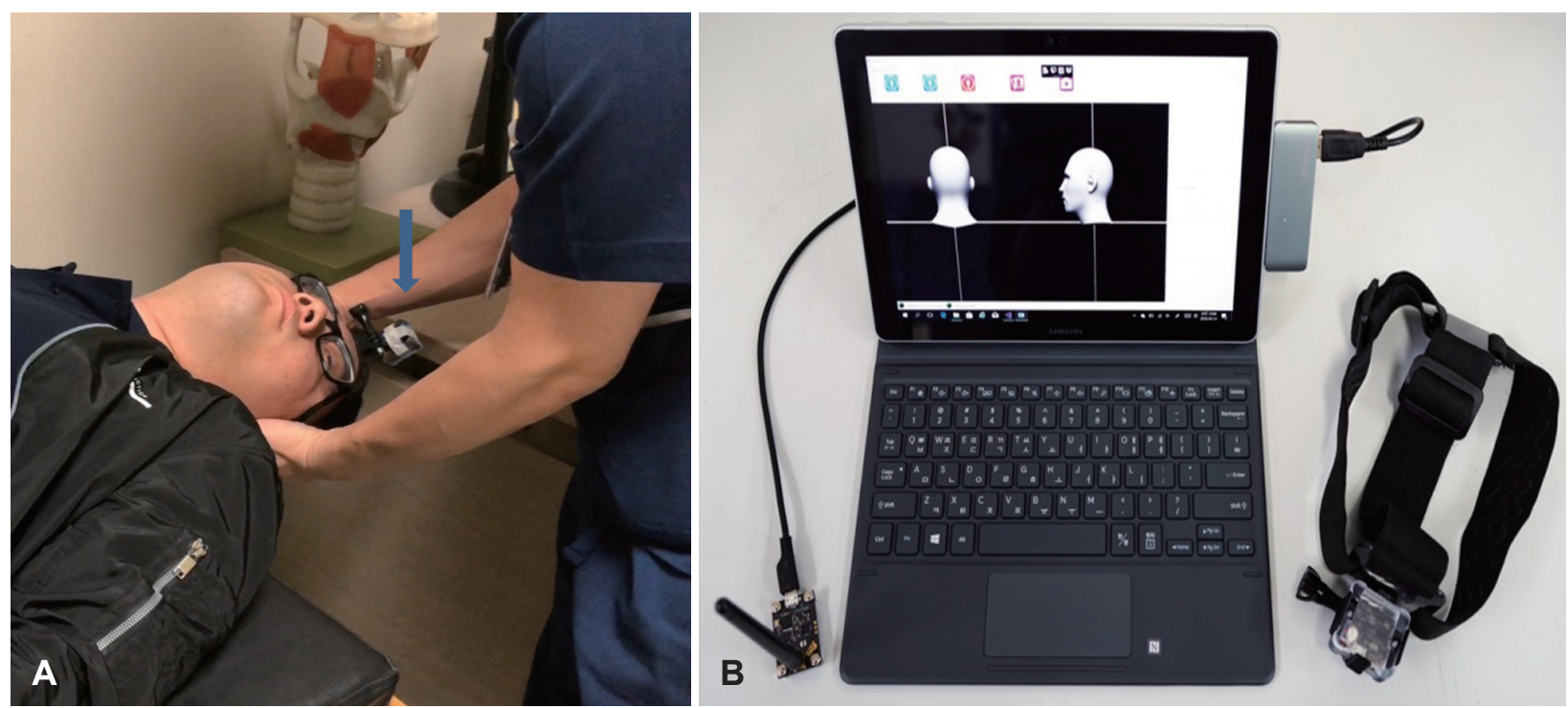

Fig. 2. The 9 axis inertial sensor is used for the collection of head position data while canalith repositioning procedure (A, arrow: the 9 axis inertial sensor attached to the hairband). The device consists of a computer, an inertial sensor, and a receiver used to collect and convert data into a human-shaped 3D model. A human-shaped 3D object can help performers noticee how much to change patients position easily (B).

가지고 있는 모션센서(Wireless AHRS module, EBIMU24G $\mathrm{V} 3$, E2Box, Seoul, Korea)를 사용하였으며, 이석정복술을 시행하기 전 환자에게 착용한 머리띠에 센서를 부착 후 각 자 세마다 머리의 위치를 분석하였으며, 머리 위치의 정보를 2.4 $\mathrm{GHz}$ wireless receiver(EBRCV24GV3, E2Box)를 이용하여 컴퓨터로 전송하여 3차원 그래픽으로 구현하였다. 각 자세에 서 목표 위치와 실제 위치 간 오차율을 벡터를 이용한 사원 수(quaternion) 방식으로 계산하였다(Fig. 2).

재평가 시점(이석정복술 1주일 후)에 비디오 안진 검사상 안진이 남아 있거나 환자의 주관적 증상을 호소할 경우 치료 지연군으로 분류하였으며, 안진과 증상 모두 호전된 경우를 치료성공군으로 분류하였다.

본 연구에서는 Epley 수기와 바비큐 회전 수기에서의 환자 의 요소[나이, body mass index(BMI)]가 치료 성공률에 영 향을 주는지 확인하기 위해 환자군을 50 세 이하와 초과군으 로 나누어 오차율에 차이가 있는지 분석하였고, $\mathrm{BMI}$ 는 25 를 기준으로 25 이하와 초과군으로 나누어 오차율에 차이가 있는지 분석하였다. 또한 가쪽 반고리관 이석증 환자에서 1 주일을 기준으로 치료성공군, 치료지연군으로 나누어 첫 번 째 이석정복술과 두 번째 이석정복술에서의 각 자세에서의 오차율에 차이가 있는지 분석하였다.

통계적 분석은 SPSS 프로그램(Version 22.0, IBM Corp., Armonk, NY, USA)을 사용하여 환자의 요소와 오차율 간의 관계, 치료성공군과 치료지연군에서의 오차율의 차이, 가쪽 반 고리관 치료지연군에서 첫 번째와 두 번째 이석정복술 시 각 자세에서의 오차율의 차이를 판단하기 위해 Mann-Whitney
Table 1. Patients demographics and variables statistics

\begin{tabular}{lccc}
\hline & PSCC & LSCC & p-value \\
\hline Age & $52.00 \pm 11.99$ & $56.99 \pm 10.30$ & 0.302 \\
Gender (M:F) & $3: 7$ & $3: 15$ & 0.774 \\
Affected side (R:L) & $6: 4$ & $11: 7$ & 0.418 \\
BMl & $23.10 \pm 4.56$ & $23.14 \pm 3.23$ & 0.955 \\
\hline
\end{tabular}

Data are presented as mean \pm standard deviation or number. LSCC: lateral semicircular canal, PSCC: posterior semicircular canal, BMl: body mass index

$\mathrm{U}$ 검정을 시행하였으며 $p$ 값이 0.05 미만일 때 통계적으로 유 의하다고 판정하였다.

본 연구는 의료기록을 검토하여 후향적 연구로 진행되었 으며, 인하대병원 연구윤리심의위원회의 승인을 얻었고 절차 를 준수하였다(IRB NO. 2020-01-018).

\section{결 과}

총 28 명의 환자 중 10 명은 뒤반고리관 이석증, 18 명은 가쪽 반고리관 이석증으로 진단받았으며, 나이, 성별, 이환된 방향, $\mathrm{BMI}$ 에서 두 군 간에 통계적으로 유의한 차이를 보이는 사항 은 없었다(Table 1).

\section{Epley 수기에 대한 분석}

28 명 중 10 명의 환자가 비디오 안진 검사상 Dix-hallpike 검 사에서 양성을 보여 Epley 수기를 시행받았으며, 자세 1 의 평균 오차율은 $10.2 \%$, 자세 2 의 평균 오차율은 $9.9 \%$, 자세 3 의 평균 오차율은 $17.8 \%$ 로 계산되었다. 전체 평균 오차율은 $12.6 \pm$ 
$5.8 \%$ 로 계산되었다. 10 명의 환자 중 6 명이 치료성공군, 4 명은 치료지연군에 포함되어 치료 성공률은 $60 \%$ 였다(Table 2).

환자의 BMI와 오차율의 상관관계에 대한 분석에서는 BMI 25 이상인 군의 오차율이 $18.67 \%$ 로 25 미만인 군의 오 차율 $10.04 \%$ 보다 통계적으로 유의하게 높게 나타났다 $(p=0.030)$. 반면 환자의 나이와 오차율의 상관관계에 대한 분석에서는 50 세를 기준으로 분류하였을 때, 50 세 이상군의 오차율은 $13.79 \%, 50$ 세 미만군의 오차율은 $9.93 \%$ 로 나이와 오차율 간에 통계학적으로 유의한 차이를 보이지 않았다 $(p=0.305)$ (Fig. 3). 치료성공군과 치료 지연군 간의 오차율 차
이에 대한 분석에서는 치료성공군에서 $9.6 \%$, 치료지연군에 서 $10.4 \%$ 로 나타나 두 군 간의 오차율 차이는 통계적으로 유 의하지 않았다 $(p=0.278)$ (Table 2).

\section{바비큐 회전 수기에 대한 분석}

28 명 중 18 명의 환자가 비디오 안진 검사상 head roll 검사에 서 양성을 보여 바비큐 회전 수기를 시행하였으며, 자세 1 의 평 균 오차율은 $9.5 \%$, 자세 2의 평균 오차율은 $9.3 \%$, 자세 3의 평 균 오차율은 $12.5 \%$, 자세 4 의 평균오차율은 $9.1 \%$, 자세 5 의 평 균 오차율은 $10.1 \%$ 로 계산되었다. 전체 평균 오차율은 $10.2 \% \pm$

Table 2. Estimated error rate of Epley maneuver in each position of successful treatment group and delayed treatment group

\begin{tabular}{lcccc}
\hline & Position 1 & Position 2 & Position 3 & Mean error rate \\
\hline Successful treatment group $(n=6), \%$ & $8.8 \pm 3.3$ & $9.2 \pm 3.7$ & $14.6 \pm 9.0$ & $10.9 \pm 5.0$ \\
Delayed treatment group $(n=4), \%$ & $12.0 \pm 7.3$ & $10.8 \pm 3.4$ & $22.5 \pm 6.9$ & $15.1 \pm 5.7$ \\
p-value & 1 & 0.286 & 0.201 & 0.286 \\
\hline
\end{tabular}

Data are presented as mean \pm standard deviation
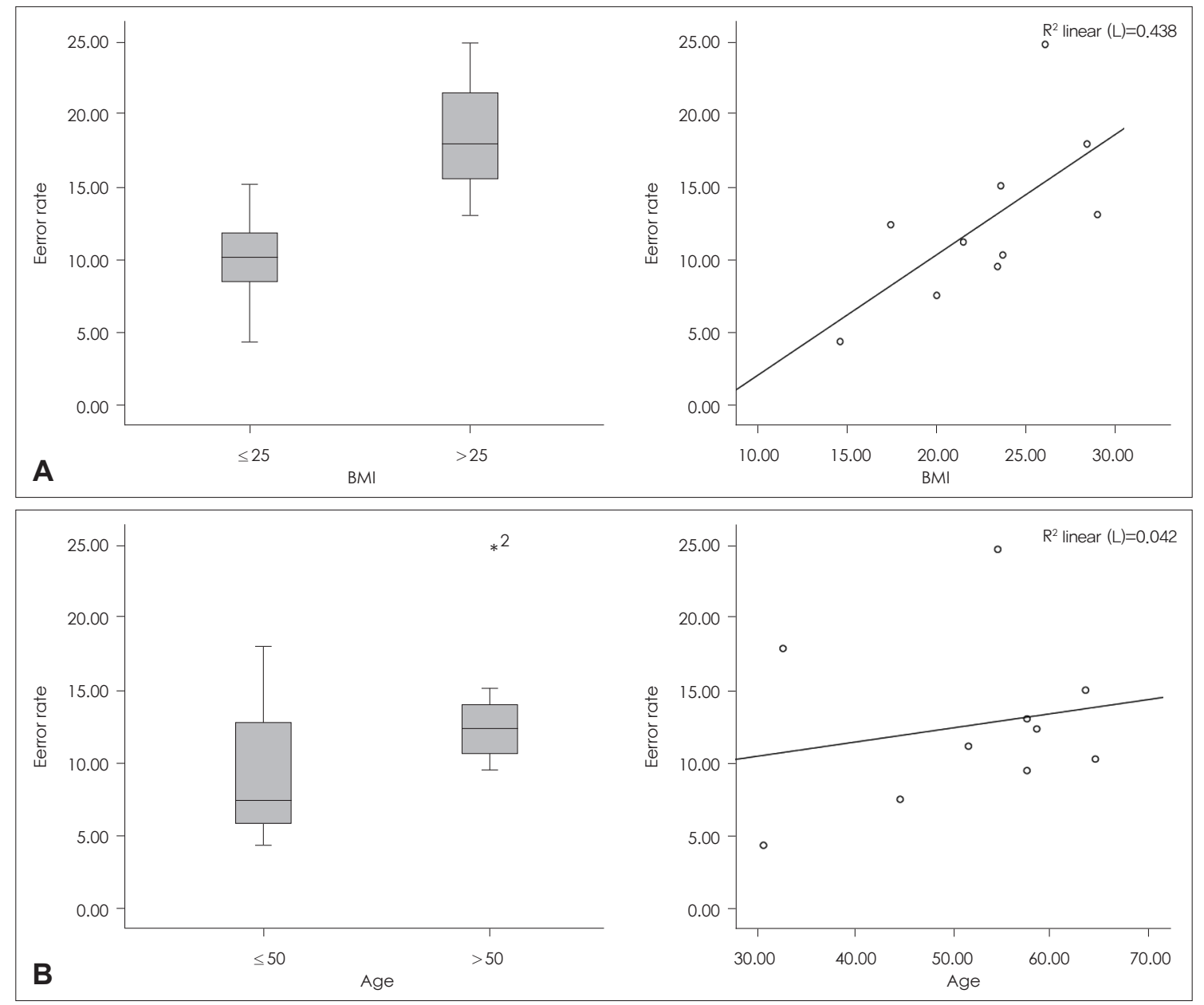

Fig. 3. The relationship between patient factors $[B M I(A)$ and age (B)] and error rates in the lateral semicircular canal benign paroxysmal positional vertigo group. In the analysis of the relationship between BMI and error rate, the group with a BMI of 25 or more showed a higher error rate than the group with a BMI of lesser than $25(\mathrm{~A})$. In the analysis of age and error rate, there was no statistically significant difference between the groups that were less than 50 years old and those who were over 50 years old (B). BMl: body mass index. 
$5.2 \%$ 로 계산되었다. 18 명의 환자 중 5 명은 치료성공군, 13 명 은 치료지연군에 포함되어 치료 성공률은 $28 \%$ 였다(Table 3).

환자의 $\mathrm{BMI}$ 와 오차율의 상관관계에 대한 분석에서는 $\mathrm{BMI} 25$ 이상인 군의 오차율이 $6.13 \%$ 로 25 미만인 군의 오 차율 $11.03 \%$ 보다 통계적 유의성을 보이지 않았다 $(p=0.110)$. 반면 환자의 나이와 오차율의 상관관계에 대한 분석에서는 50 세를 기준으로 분류하였을 때, 50세 이상군의 오차율은 $11.28 \%, 50$ 세 미만군의 오차율은 $6.5 \%$ 로 나이와 오차율 간 에 통계학적으로 유의한 차이를 보이지 않았다 $(p=0.080)$ (Fig. 4). 치료성공군과 치료지연군 간의 오차율 차이에 대한
분석에서는 치료성공군에서 $9.6 \%$, 치료지연군에서 $10.4 \%$ 로 나타나 두 군 간의 오차율 차이는 통계적으로 유의하지 않 았다 $(p=0.958)$ (Table 3).

\section{가쪽 반고리관(Lateral semicircular canal) $\mathrm{BPPV}$ 환자 중 치료지연군에 대한 분석}

가쪽 반고리관 BPPV로 바비큐 회전 수기를 시행받은 환자 중 재평가 시점인 1 주일 후에도 증상 및 안진이 남아 있는 환 자를 대상으로 시행한 분석은 첫 번째 이석정복술 시의 오차 율과 두 번째 이석정복술을 시행했을 때의 오차율을 계산하여

Table 3. Estimated error rate of barbecue maneuver in each position of successful treatment group and delayed treatment group

\begin{tabular}{lcccccc}
\hline & Position 1 & Position 2 & Position 3 & Position 4 & Position 5 & Mean error rate \\
\hline Successful treatment group $(n=5), \%$ & $10.7 \pm 4.2$ & $8.9 \pm 5.7$ & $10.1 \pm 5.1$ & $8.7 \pm 3.0$ & $9.8 \pm 4.6$ & $9.6 \pm 4.2$ \\
Delayed treatment group $(n=13), \%$ & $8.9 \pm 4.8$ & $9.4 \pm 5.2$ & $13.3 \pm 8.8$ & $9.2 \pm 5.3$ & $10.2 \pm 4.3$ & $10.4 \pm 5.2$ \\
p-value & 0.595 & 0.832 & 0.633 & 0.671 & 0.243 & 0.958 \\
\hline
\end{tabular}

Data are presented as mean \pm standard deviation
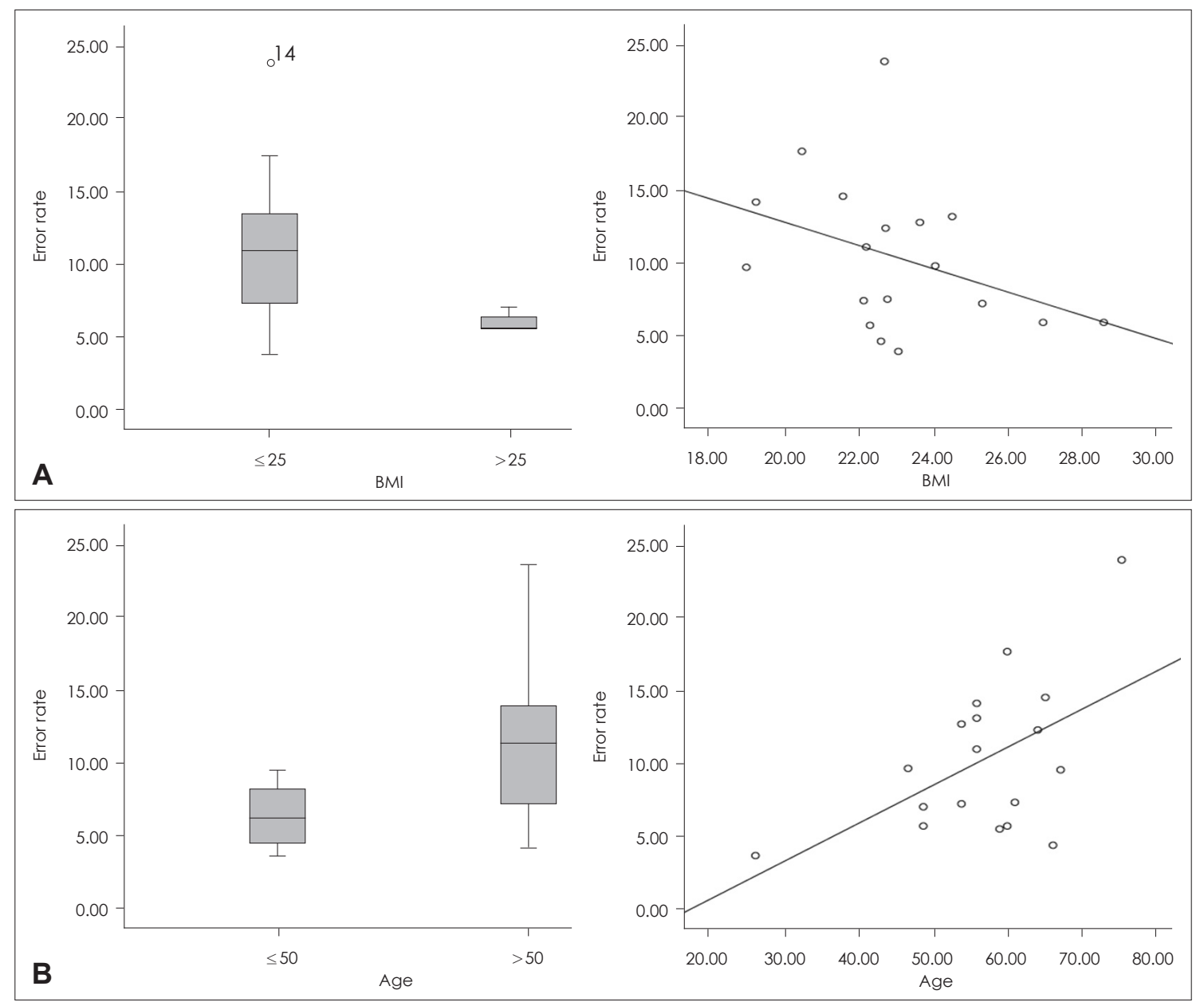

Fig. 4. The relationship between patient factors $[B M I(A)$ and age $(B)]$ and error rates in the lateral semicircular canal benign paroxysmal positional vertigo group. In the analysis of the relationship between $\mathrm{BMI}$ and error rate, there was no statistically significant difference between the group with a BMI of 25 or more and the group with a BMI of lesser than 25 (A). In the analysis of age and error rate, there was no statistically significant difference between the groups that were less than 50 years old and those who were over 50 years old (B). BMI: body mass index. 
비교하였다. 전체 이석정복술의 오차율은 첫 번째 이석정복술 시 $13.0 \pm 3.63 \%$, 두 번째 이석정복술 시 $10.83 \% \pm 3.76 \%$ 로 측정 되어 통계적으로 유의한 차이를 보이지 않았다 $(p=0.290)$. 각 자세별로 나누어 오차율을 분석한 결과는 자세 1 의 경우 첫 번째 이석정복술 시 $10.5 \%$, 두 번째 이석정복술 시 $11.6 \%$ 로 측 정되었으며 $(p=0.195)$, 자세 2는 첫 번째 이석정복술 시 $11.8 \%$,
두 번째 이석정복술 시 $9.1 \%$ 로 측정되었고 $(p=0.807)$ 자세 3은 첫 번째 이석정복술 시 $12.6 \%$, 두 번째 이석정복술시 $13 \%$ 로 측 정되었다 $(p=0.871)$. 자세 4 의 경우 첫 번째 이석정복술 시 $17.33 \%$, 두 번째 이석정복술 시 $8.16 \%$ 로 측정되었으며 $(p=$ 0.688), 자세 5는 첫 번째 이석정복술 시 $13.1 \%$, 두 번째 이석정 복술 시 $12.5 \%$ 로 측정되었다 $(p=0.054)$ (Fig. 5, Table 4).
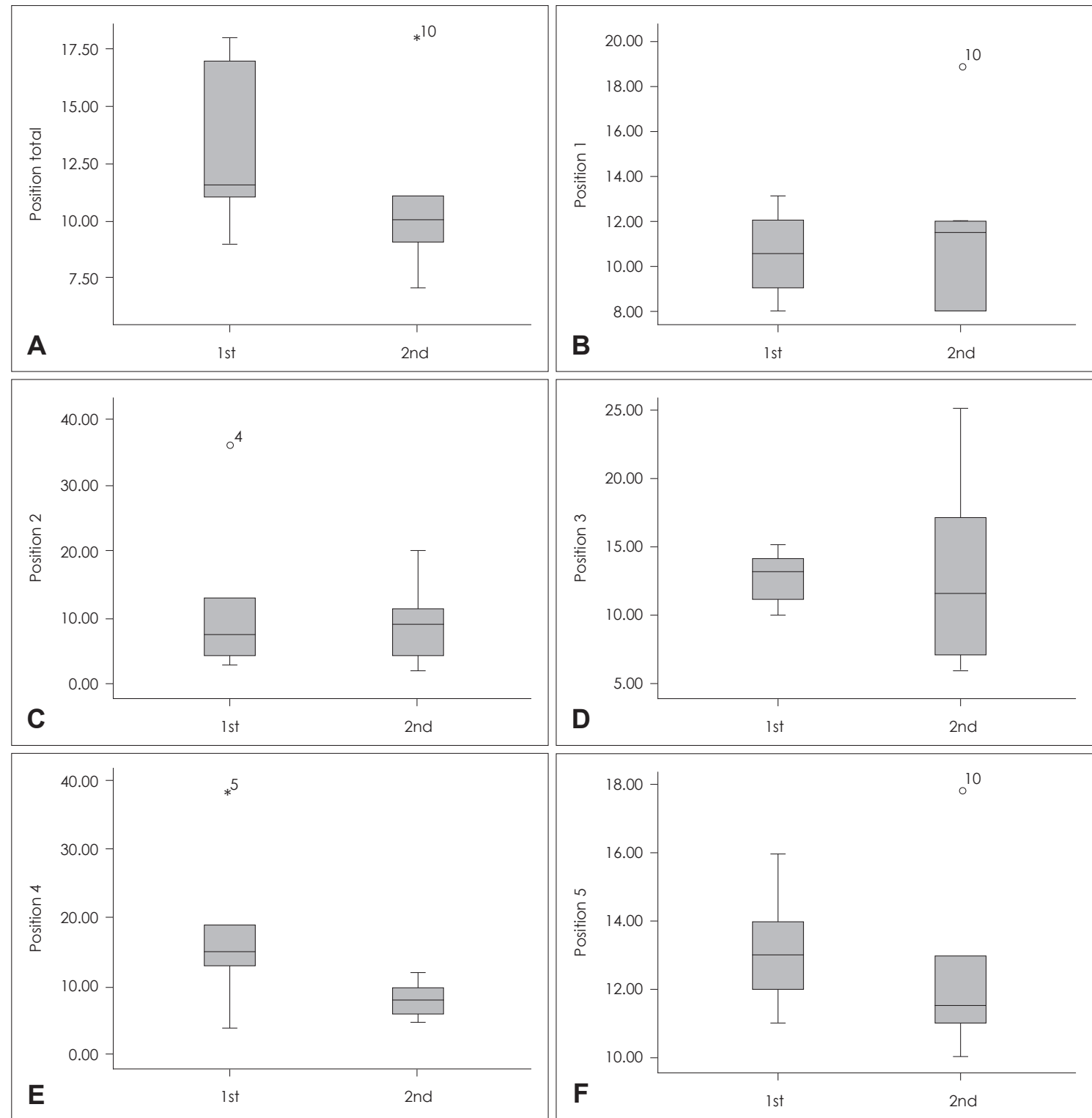

Fig. 5. Comparison of the error rate between 1st and 2nd maneuvers of delayed treatment group. There was statistically significant difference in the mean error rate $(A)$ and the error rate of each position (B-F) between the first and second maneuvers in the treatment delay group of the barbecue maneuver patients.

Table 4. Estimated error rate of $1 \mathrm{st}$ and $2 \mathrm{nd}$ barbeque maneuver in each position in delayed treatment group $(\mathrm{n}=6)$

\begin{tabular}{lcccccc}
\hline & Position 1 & Postion 2 & Position 3 & Position 4 & Position 5 & Mean error rate \\
\hline 1st maneuver, \% & $10.5 \pm 1.8$ & $11.8 \pm 12.5$ & $12.6 \pm 1.8$ & $17.3 \pm 11.3$ & $13.2 \pm 1.7$ & $13.0 \pm 3.6$ \\
2nd maneuver, \% & $11.6 \pm 4.0$ & $9.2 \pm 6.4$ & $13.0 \pm 7.0$ & $8.2 \pm 2.5$ & $12.5 \pm 2.8$ & $10.8 \pm 3.7$ \\
p-value & 0.195 & 0.807 & 0.871 & 0.688 & 0.054 & 0.290 \\
\hline
\end{tabular}

Data are presented as mean \pm standard deviation 


\section{고 찰}

최근 초소형 미세공정 시스템(microelectromechanical systems)이 발전하면서 관성센서를 통한 연구가 급속도로 발 전하였으며, 의학 분야에서도 이를 이용한 연구들이 활발히 이루어지고 있다. 관성센서는 가속도계(accelerometer)와 자 이로스코프(gyroscopes)으로 이루어져 보통 관성측정장비 (inertial measurement units)와 결합되어 사용된다. 최근 가 격이 저렴해졌으며, 가볍고, 작고, 좋은 휴대성 등의 이점이 있어 간접적 또는 직접적으로 모션을 다루는 모든 활동에서 널리 사용되고 있다. 또한, 복잡한 모션을 분석하기 위해 관 성센서에 의해 수집된 데이터를 처리하는 방법도 여러 분야 에서 개발되어 발전되고 있다. 특히 어지럼 환자에서 걸음걸 이를 분석하는 데 이용되거나 스포츠의학, 재활 의학 분야 등에서 사용되고 있다. ${ }^{15-17)}$

$\mathrm{BPPV}$ 는 가장 흔한 전정 질환이며, 증상이 갑자기 생기고 저절로 호전되는 경우가 많기 때문에 실제로는 발생률이 더 높을 것으로 생각되는 질환이다. ${ }^{18)}$ 또한 $\mathrm{BPPV}$ 는 중한 질환 으로 여겨지지 않지만, $\mathrm{BPPV}$ 의 증상이 환자의 삶의 질을 현 저히 낮출 수 있으며, 환자의 직장이나 학교에서의 업무 효율 성에 큰 영향을 주고 일상생활에서의 문제들을 일으키기도 한다. ${ }^{1920)}$ 또한 외래와 응급실에의 잦은 내원과 전문과 협진 등으로 의료 시스템상에서도 많은 부담이 되는 질환이다. $\mathrm{BPPV}$ 의 치료로 이석정복술이 효과적으로 증상을 완화시키 지만 재발이 굉장히 흔한 질환으로, 증상이 생길 때마다 병 원을 방문하는 것은 시간적, 경제적으로 환자에게 부담을 주 게 된다.

최근 $\mathrm{BPPV}$ 의 치료 정확도를 높이기 위한 도구들이 개발 되었는데, 대표적으로 DizzyFIX(Clearwater Clinical Limited, alberta, Canada)가 있으며, 환자가 쓰는 모자에 투명한 관으로 구성된 구조물이 있고 안은 액체와 입자들이 있어, 환자가 이석정복술을 시행하며 머리의 위치를 바꾸면 관 안 의 입자들이 움직이며 정확한 위치와 시간을 보조해주는 장 치이다. ${ }^{21)}$ Virtual reality epley maneuver system(VREMS) 은 가상현실을 이용하여 시각과 청각으로 이석정복술의 각 단계를 도와주는 도구로, 집에서 환자 스스로 이석정복술을 시행할 때 VREMS를 이용하는 것이 더 정확하다는 결과를 발표하였다. 22

이전의 연구들에서 제시한 BPPV 환자의 치료에 영향을 주는 요소로는 바이러스성 내이 질환, 두부 외상, 메니에르병 의 동반, 증상이 지속 기간, 이환된 반고리관의 개수, 양측성 $\mathrm{BPPV}$ 등이 있으나, ${ }^{13,23,24)}$ 표준화된 치료 방식이 정립되지 않 았고, 연구마다 다른 결과를 보여 아직 논쟁 중에 있다. 이전
의 연구들이 대부분 환자가 가지고 있는 요소나 동반 질환 등에 중심을 둔 연구였다면, 본 연구는 이석정복술 자체의 정확도와 오차율에 대한 분석과 오차율에 영향을 줄 수 있 는 환자의 요소들에 대한 첫 번째 연구이다.

$\mathrm{BPPV}$ 환자의 치료는 이석정복술이 가장 효과적으로 사용 되고 있으며, ${ }^{5)}$ 이석정복술의 1 회 치료로 실패한 경우는 12 56\%로 보고되고 있다. ${ }^{12,25)}$ 본 연구에서는 가쪽 반고리관 $\mathrm{BPPV}$ 의 경우 1 회의 치료로 회복된 경우가 18 명의 환자 중 5 명 (27.8\%)으로 나타났으며, 뒤반고리관 BPPV의 경우 1 회의 치료 로 회복된 경우가 10 명 중 6 명(60\%)으로 나타났으며, 이는 가 쪽 반고리관 $\mathrm{BPPV}$ 의 경우 $\mathrm{Kim}$ 등 ${ }^{26}$ 이 2015 발표한 가쪽반고 리관 $\mathrm{BPPV}$ 환자의 1 회 치료 시의 성공률 $74.1 \%$ 보다 낮은 성공 률을 보였고, 뒤반고리관의 경우도 2018년 $\mathrm{Kim}^{27}$ 이 발표한 뒤 반고리관 BPPV 환자의 1회 치료 시의 성공률 $57.6 \%$ 보다 낮은 성공률을 보였다.

뒤반고리관 $\mathrm{BPPV}$ 환자군의 경우 환자의 요소와 오차율 의 상관관계를 분석하면, 환자의 BMI가 높을수록 오차율이 높아지는 결과를 보였으며, 이는 Epley 수기의 자세가 목을 뒤쪽으로 넘기는 자세(Fig. 1)를 포함하고 있어 연관성이 있 을 것으로 생각된다. 가쪽 반고리관 $\mathrm{BPPV}$ 환자군의 경우 $\mathrm{BMI}$ 와 나이 모두 통계적을 유의한 차이를 보이지 않았다. 본 연구에서 이전의 보고에 비해 가쪽 반고리관 $\mathrm{BPPV}$ 의 치 료 성공률이 낮게 나타나, 이에 대한 분석을 위해 가쪽 반고 리관 $\mathrm{BPPV}$ 의 치료지연군에서의 첫 번째와 두 번째 이석정 복술의 오차율을 계산한 결과, 평균 오차율은 $13 \%$ 에서 $10.8 \%$ 로 감소하였으며, 특히 자세 4(Fig. 1)에서의 오차율이 첫 번째 이석정복술과 두 번째 이석정복술 사이에 통계적으 로 유의하진 않지만, 큰 차이를 보였다. 임상에서 실제로 Epley 수기를 시행할 시 환자가 자세 4를 정확하게 하는 것 이 가장 어려우며, 환자가 1 주일 후 재내원하여 이석정복술 을 시행받을 때 이전에 치료를 받았던 적이 있으므로 학습효 과로 인해 두 번째 이석정복술 시행 시 오차율을 줄일 수 있 었다고 생각할 수 있다.

본 연구에서 관성센서를 이용한 오차율의 측정은 모든 과 정에서 검사상의 오류를 줄이기 위해 노력하였다. 오일러각 (Euler angles)를 이용하여 머리의 위치를 계산하였을 때는 짐벌락(gimbal lock)이 발생하는 문제가 있었으며, 3차원적 으로 각 축마다 원점을 설정하는 것에는 항상 처음 머리 위 치 설정에 오류가 발생하였다. 사원수 방식으로 이용하여 사 람마다 시작 시의 머리의 위치를 원점으로 설정하여 벡터값 을 이용하여 목표 위치와 실제 위치 간의 오차율을 계산하 여 정확도를 높이고자 하였다.

소프트웨어 프로그램도 단순히 숫자로 오차율을 계산하 
는 것을 넘어 3 차원 그래픽 구현을 시도하여 실제로 이석정 복술을 시행하며 눈으로 보며 검사의 정확도를 판단하고 조 정하여 오차를 줄일 수 있도록 개발하여 실제 임상에서 유용 하게 사용할 수 있도록 하였다. 관성센서를 이용한 이러한 방 식이 VREMS 등과 결합한다면 단순히 환자에게 이석정복술 의 순서를 가이드 해주는 것뿐만 아니라 현재 환자의 두위를 파악하여 정확한 목표 머리의 위치를 가이드 해줄 수 있어, 추후 병원에 내원하지 않고 스스로 이석증을 진단하고 치료 하는 방법도 개발될 수 있을 것으로 생각된다. 또한 추후 이 석정복술 각 단계의 시간이나 속도 등의 다른 인자들도 치료 율에 영향을 주는지에 대한 연구도 시행할 수 있을 것이다.

본 연구의 한계점으로는 많은 수의 환자를 대상으로 시행 하지 못했다는 점이 있다. 더 많은 수의 환자를 대상으로 전 향적 연구를 시행한다면 더 정확한 데이터를 얻어 신뢰할 만 한 결과를 낼 수 있을 것으로 사료된다.

Epley 수기에서 BMI가 높은 환자군의 오차율이 BMI가 낮은 환자군의 오차율보다 더 큰 것으로 나타났다. 치료 지 연군에서 반복적인 바비큐 회전 수기를 시행할 때 학습효과 로 더 정확한 자세를 취할 수 있었을 것으로 생각된다. 이석 정복술 시행 시에는 환자의 BMI나 나이 같은, 환자 요소를 고려하여 시행하면 성공률을 높이는 데 도움이 될 것으로 사료되며, 관성센서를 이용한 연구들이 앞으로 더 이루어진 다면, 이석증 환자에서 이석정복술 시행 시에 정확도를 높이 는 데 기여할 수 있을 것으로 기대된다.

\section{Acknowledgments}

This research was supported by Basic Science Research Program through the National Research Foundation of Korea (NRF) funded by the Ministry of Education (No. 2018R1A6A1A03025523).

\section{Author Contribution}

Conceptualization: Kyu-Sung Kim, Sangmin Lee, Hyung Sun Hong. Data curation: Hyung Sun Hong, Ki Nam Kim, Chang Bin Yun. Formal analysis: Hyung Sun Hong, Jin Gu Kang. Funding acquisition: Sangmin Lee, Kyu-Sung Kim. Investigation: Hyung Sun Hong, Ki Nam Kim. Methodology: Hyun Ji Kim. Project administration: Hyun Ji Kim, Jin Gu Kang, Hyung Sun Hong. Resources: Kyu-Sung Kim, Hyun Ji Kim. Software: Jin Gu Kang, Sangmin Lee. Supervision: Sangmin Lee, Kyu-Sung Kim. Validation: KyuSung Kim, Jin Gu Kang, Hyung Sun Hong. Visualization: Ki Nam Kim, Chang Bin Yun, Jin Gu Kang. Writing - original draft: Hyung Sun Hong, Hyun Ji Kim, Kyu-Sung Kim. Writing — review \& editing: Kyu-Sung Kim, Hyung Sun Hong.

\section{ORCIDs}

Kyu-Sung Kim

https://orcid.org/0000-0002-5650-3526

Sangmin Lee

\section{REFERENCES}

1) Katsarkas A. Benign paroxysmal positional vertigo (BPPV):

Idiopathic versus post-traumatic. Acta Otolaryngol 1999;119(7): 745-9.

2) Hanley K, O'Dowd T, Considine N. A systematic review of vertigo in primary care. Br J Gen Pract 2001;51(469):666-71.

3) Lynn S, Pool A, Rose D, Brey R, Suman V. Randomized trial of the canalith repositioning procedure. Otolaryngol Head Neck Surg 1995;113(6):712-20.

4) Burton MJ, Eby TL, Rosenfeld RM. Extracts from the Cochrane Library: Modifications of the Epley (canalith repositioning) maneuver for posterior canal benign paroxysmal positional vertigo. Otolaryngol Head Neck Surg 2012;147(3):407-11.

5) Bhattacharyya N, Baugh RF, Orvidas L, Barrs D, Bronston LJ, Cass S, et al. Clinical practice guideline: Benign paroxysmal positional vertigo. Otolaryngol Head Neck Surg 2008;139(5 Suppl 4): S47-81.

6) Epley JM. The canalith repositioning procedure: For treatment of benign paroxysmal positional vertigo. Otolaryngol Head Neck Surg 1992;107(3):399-404.

7) Kim JS, Oh SY, Lee SH, Kang JH, Kim DU, Jeong SH, et al. Randomized clinical trial for geotropic horizontal canal benign paroxysmal positional vertigo. Neurology 2012;79(7):700-7.

8) Lopez-Escamez JA, Gamiz MJ, Fernandez-Perez A, GomezFiñana M. Long-term outcome and health-related quality of life in benign paroxysmal positional vertigo. Eur Arch Otorhinolaryngol 2005;262(6):507-11.

9) Sakaida M, Takeuchi K, Ishinaga H, Adachi M, Majima Y. Longterm outcome of benign paroxysmal positional vertigo. Neurology 2003;60(9):1532-4.

10) Rashad UM. Long-term follow up after Epley's manoeuvre in patients with benign paroxysmal positional vertigo. J Laryngol Otol 2009;123(1):69-74.

11) Kansu L, Avci S, Yilmaz I, Ozluoglu LN. Long-term follow-up of patients with posterior canal benign paroxysmal positional vertigo. Acta Otolaryngol 2010;130(9):1009-12.

12) Macias JD, Lambert KM, Massingale S, Ellensohn A, Fritz JA. Variables affecting treatment in benign paroxysmal positional vertigo. Laryngoscope 2000;110(11):1921-4.

13) Del Rio M, Arriaga MA. Benign positional vertigo: Prognostic factors. Otolaryngol Head Neck Surg 2004;130(4):426-9.

14) Teixido M, Woods O, Kung B, Seyyedi M. A 3D benign paroxysmal positional vertigo model for study of otolith disease. World J Otorhinolaryngol Head Neck Surg 2016;2(1):1-6.

15) Fong DT, Chan YY. The use of wearable inertial motion sensors in human lower limb biomechanics studies: A systematic review. Sensors (Basel) 2010;10(12):11556-65.

16) Muro-de-la-Herran A, Garcia-Zapirain B, Mendez-Zorrilla A. Gait analysis methods: An overview of wearable and non-wearable systems, highlighting clinical applications. Sensors (Basel) 2014;14(2):3362-94.

17) Vienne A, Barrois RP, Buffat S, Ricard D, Vidal PP. Inertial sensors to assess gait quality in patients with neurological disorders: A systematic review of technical and analytical challenges. Front Psychol 2017;8:817.

18) Yardley L, Putman J. Quantitative analysis of factors contributing to handicap and distress in vertiginous patients: A questionnaire study. Clin Otolaryngol Allied Sci 1992;17(3):231-6.

19) Gopinath B, McMahon CM, Rochtchina E, Mitchell P. Dizziness and vertigo in an older population: The Blue Mountains prospective cross-sectional study. Clin Otolaryngol 2009;34(6):552-6.

20) Neuhauser HK, Radtke A, von Brevern M, Lezius F, Feldmann M, Lempert T. Burden of dizziness and vertigo in the community. Arch Intern Med 2008;168(19):2118-24.

21) Bromwich M, Hughes B, Raymond M, Sukerman S, Parnes L. Efficacy of a new home treatment device for benign paroxysmal 
positional vertigo. Arch Otolaryngol Head Neck Surg 2010;136(7): $682-5$.

22) Tabanfar R, Chan HHL, Lin V, Le T, Irish JC. Development and face validation of a Virtual Reality Epley Maneuver System (VREMS) for home Epley treatment of benign paroxysmal positional vertigo: A randomized, controlled trial. Am J Otolaryngol 2018;39(2):184-91.

23) Karlberg M, Halmagyi GM, Büttner U, Yavor RA. Sudden unilateral hearing loss with simultaneous ipsilateral posterior semicircular canal benign paroxysmal positional vertigo: A variant of vestibulo-cochlear neurolabyrinthitis? Arch Otolaryngol Head Neck Surg 2000;126(8):1024-9.
24) Tanimoto H, Doi K, Nishikawa T, Nibu K. Risk factors for recurrence of benign paroxysmal positional vertigo. J Otolaryngol Head Neck Surg 2008;37(6):832-5.

25) Furman JM, Cass SP. Benign paroxysmal positional vertigo. N Engl J Med 1999;341(21):1590-6.

26) Kim C-S, Choi H-Y, Kwon P-S, Lee E-P, Seo C-W. Factors analysis affecting lateral canal benign paroxysmal positional vertigo. Korean J Clin Lab Sci 2015,47(1):35-8.

27) Kim C-S. Analysis of the factors affecting canalith repositioning maneuver treatment of in posterior canal benign paroxysmal positional vertigo of a dizziness patient. Korean J Clin Lab Sci 2018;50(3):267-74. 